\title{
Highly-Controllable Imprinted Polymer Nanoshell on the Surface of Silica Nanoparticles for Selective Adsorption of $17 \beta$-Estradiol
}

\author{
Xue Fu1,2* , Bo Song ${ }^{1,2^{*}}$, Xiaozhen Chen², An Wang1\#, Chun Wang2\# \\ ${ }^{1}$ College of Architecture and Environment, Sichuan University, Chengdu, China \\ ${ }^{2}$ Chengdu Institute of Biology, Chinese Academy of Sciences, Chengdu, China \\ Email: "wangchun@cib.ac.cn, "wangan2218@163.com
}

How to cite this paper: Fu, X., Song, B., Chen, X.Z., Wang, A. and Wang, C. (2018) Highly-Controllable Imprinted Polymer Nanoshell on the Surface of Silica Nanoparticles for Selective Adsorption of $17 \beta$-Estradiol. Journal of Encapsulation and Adsorption Sciences, 8, 210-224.

https://doi.org/10.4236/jeas.2018.84011

Received: September 17, 2018

Accepted: November 17, 2018

Published: November 20, 2018

Copyright $\odot 2018$ by authors and Scientific Research Publishing Inc. This work is licensed under the Creative Commons Attribution International License (CC BY 4.0).

http://creativecommons.org/licenses/by/4.0/

(C) (i) Open Access

\begin{abstract}
A highly-controllable core-shell silica-MIPs absorbent by anchoring a MIPs layer to the surface of $\mathrm{SiO}_{2}$ nanoparticles via a surface molecular imprinting process was prepared. The templates were covalently modified with functional monomers to form precursor EstSi. The latter together with coupling reagent $\mathrm{KH}-570$, were grafted onto the surface of $\mathrm{SiO}_{2}$ nanoparticles before polymerization, to ensure the quantity and quality of imprinted sites on the surface of the covalently attached matrix. The as-synthesized core-shell nanomaterials $\left(\mathrm{SiO}_{2} @ \mathrm{MIP} 2\right)$ were then evaluated for selective adsorption of $17 \beta$-estradiol (E2) with Raman spectra as detection method. The results indicate that $\mathrm{SiO}_{2} @ \mathrm{MIP} 2$ can fast and selectively adsorb E2 from structural analogues, with detection limit of $0.01 \mu \mathrm{mol} / \mathrm{l}$.
\end{abstract}

\section{Keywords}

Surface-Imprinting, Core-Shell Nanoparticle, Selective Adsorption, $17 \beta$-Estradiol

\section{Introduction}

$17 \beta$-estradiol (E2) is one of the several naturally occurring estrogens, which possesses a series of threats to wildlife and humans [1] [2]. Due to its persistence and accumulation in the environment, numerous methods have been developed to decontaminate E2, such as adsorption [3], catalytic degradation [4] [5] oxidation [6] and biodegradation [7] [8] [9]. Among which adsorption is a commonly

*These authors contributed equally to this work.

\#Corresponding author. 
adapted approach due to its relatively convenience and efficiency.

However, absorbent materials have been reported are still suffering drawbacks of slow adsorption rate, non-specific adsorption and complicated preparation process etc.

Silica nanoparticles have attracted great attention for their low toxicity, excellent chemical stability, and moderately modifiable surface [10]. The large surface area and functionalized hydroxyl groups on particle surface underlie facile modification and high loading effect of various absorbents [11] [12], which allows us to tune the scales and endow them with novel properties.

Molecular imprinting has been widely used for the development of tailor-made receptor binding sites in a three-dimensional, cross-linked polymer matrix. Molecularly imprinted polymers (MIPs) are thus generated with ligand-specific recognition properties analogous to biological systems, and have gained considerable attention in applications, such as solid-phase extraction [13] [14] [15], chiral compounds isolation [16] [17], sensors [18] catalysis [19] [20] and synthetic auxiliary [21]. Despite its wide applications and numerous fabrication methods of the conventional bulk MIPs, it still suffers some intrinsic limitations: the deep buried binding sites in bulk hinder subsequent template removal and the guest molecule diffusion process, thereby decreasing the imprinting efficiency; the mechanically crushing and grinding can cause the destruction of imprinted sites and cavities, resulting in the irregular shape, inhomogeneous imprinting sites and eventually poor site accessibility and low adsorption capacity to the guest molecule. In response to these intrinsic drawbacks, the surface imprinting technique has been proposed by creating the imprinted cavities with high affinity on the surface of a suitable matrix, which not only possesses high adsorption capacity but also avoids problems of limited mass transfer and template removal.

Several methodologies are adapted to prepare such MIP films include spin-coating [22] and surface-initiated atom transfer radical polymerization (ATRP) [23]. One major issue with these approaches is controlling the MIP film thickness while ensuring the quantity and quality of imprinting sites. Therefore, finding a facile way to fabricate robust and efficient nanostructured molecular imprinting systems is still greatly needed.

As is well known, various analytical methods have been applied in estrogen detection such as high-performance liquid chromatography (HPLC), gas chromatography-mass spectrometry (GC-MS), enzyme-linked immunosorbent assay (ELISA) and some other analytical tools. Although some of these analytical techniques are widely used with good precision, their applications are seriously restricted due to the complicated and professional operation procedures, high cost and relative low sensitivity. Due to the excellent sensitivity, fast response, rich molecular information and non-destructive data acquisition, Raman is extensively used from biological analysis to environment monitoring and food safety, even clinical diagnosis and therapy. It could be a promising idea to com- 
bine MIPs with SERS for the selective adsorption and sensitive detection of estradiol.

In this work, we report a facile approach to prepare a highly-controllable core-shell silica-MIPs absorbent. The covalently modified templates along with $\mathrm{KH}-570$ were grafted onto the surface of $\mathrm{SiO}_{2}$ nanoparticles and followed by polymerization. Thus, a MIPs layer was anchored on the surface of $\mathrm{SiO}_{2}$ nanoparticles via a surface molecular imprinting process. The performance of the as-synthesized materials towards E2 and their selectivity to structural analogues were investigated, which revealed that the core-shell MIP nanomaterial coupled with Raman, could be applied to the selective adsorption and sensitive detection of estradiol.

\section{Experimental}

\subsection{Reagents and Chemicals}

All chemicals were of analytical grade reagents. Tetraethylorthosilicate (TEOS) was purchased from Gracia Chemical Technology Co., Ltd. Triethylamine (TEA), 3-methacryloxypropyltrimethoxysilane (KH-570),

3-isocyanatopropyltriethoxy-silane (IPTES) and acrylic acid (MAA) were supplied from Shanghai Aladdin Industrial Corporation. 17 $\beta$-Estradiol (E2) was purchased from Adamas Reagent, Ltd. Ethylene glycol dimethyl acrylate (EGDMA) and 2,2'-Azobis (2 methylpropionitrile) (AIBN) were obtained from Guangdong J\&K Scientific Ltd. Acetonitrile (ACN), tetrahydrofuran (THF), toluene were purchased from Sichuan Xilong Chemical Co., Ltd. Ammonia solution $(25 \%-28 \%)$, ethanol, methanol and acetone were obtained from Sichuan Kelong Chemical Co., Ltd. Ultrapure water (UPW) was used throughout the experimental procedures. Co., Ltd.

\subsection{Preparation of $\mathrm{SiO}_{2}$ Nanoparticles $\left(\mathrm{SiO}_{2} \mathrm{NPs}\right)$}

$\mathrm{SiO}_{2} \mathrm{NPs}$ were prepared by the Stöber method [24]. Ethanol (44 ml), water (11 $\mathrm{mL}$ ), and ammonia solution $(1.1 \mathrm{~mL})$ were mixed in a flask and vigorously stirred at $40^{\circ} \mathrm{C}$. Then a mixing solution of TEOS $(4.4 \mathrm{~mL})$ and ethanol $(20 \mathrm{~mL})$ was quickly added to the above solution and the mixture was stirred for $15 \mathrm{~h}$. The $\mathrm{SiO}_{2} \mathrm{NPs}$ were centrifuged and rinsed with acetone. Finally, the obtained $\mathrm{SiO}_{2} \mathrm{NPs}$ were dried at $120^{\circ} \mathrm{C}$ for $24 \mathrm{~h}$.

\subsection{Anchoring of $\mathrm{E} 2$ and $\mathrm{KH}-570$ on the Surface of $\mathrm{SiO}_{2} \mathrm{NPS}$}

First, the template-functional monomer complex (EstSi) was prepared: E2 (1 mmol), IPTES ( $1.3 \mathrm{mmol})$, and TEA $(8 \mathrm{mmol})$ were dissolved in THF. The mixture was stirred under $\mathrm{N}_{2}$ at $65^{\circ} \mathrm{C}$ for $24 \mathrm{~h}$. The reaction solution was concentrated under reduced pressure, and the residue was purified by precipitation in $\mathrm{n}$-hexane and filtration [25]. EstSi was collected as a white solid (70 mg).

$\mathrm{SiO}_{2}-(\mathrm{E} 2+\mathrm{KH}-570)$ were prepared by covalently attachment of $\mathrm{KH}-570$ and EstSi to the surface of $\mathrm{SiO}_{2}$ nanoparticle. Firstly, the $\mathrm{SiO}_{2} \mathrm{NPs}$ were dispersed in 
dry toluene ( $75 \mathrm{~mL}$ per gram of particles) under inert conditions. Then, EstSi ( $0.5 \mathrm{mmol}$ per gram of particles) and $\mathrm{KH}-570$ ( $1 \mathrm{mmol}$ per gram of particles) were added to the suspension under constant stirring. The mixture was refluxed at $90^{\circ} \mathrm{C}$ for $24 \mathrm{~h}$. The resultant nanoparticles were centrifuged, filtered and washed several times with acetone. The solids were vacuum dried at $60^{\circ} \mathrm{C}$ for 24 $\mathrm{h}$ to obtain $0.95 \mathrm{~g}$ of $\mathrm{SiO}_{2}-(\mathrm{E} 2+\mathrm{KH}-570)$. The $\mathrm{SiO}_{2}$-(IPTES+KH-570) were prepared by the same conditions, except that IPTES $(0.5 \mathrm{mmol}$ per gram of particles) was used instead of EstSi ( $0.5 \mathrm{mmol}$ per gram of particles).

\subsection{Preparation of $17 \beta$-Estradiol-Imprinted $\mathrm{SiO}_{2} @ \mathrm{MIP}$ NPs}

The above prepared $\mathrm{SiO}_{2}-(\mathrm{E} 2+\mathrm{KH}-570)(150 \mathrm{mg})$ were dispersed into $35 \mathrm{~mL}$ of THF under ultrasonication. MAA (0.1 mmol), EGDMA and AIBN (15 mg) were subsequently dissolved into this solution. The mixing solution was purged with nitrogen for $10 \mathrm{~min}$. Polymerization was first done at $50^{\circ} \mathrm{C}$ for $5 \mathrm{~h}$, and subsequently at $60^{\circ} \mathrm{C}$ for $24 \mathrm{~h}$. The mixing solution was stirred at a rate of 300 $\mathrm{rpm} / \mathrm{min}$ throughout the experiment. Then particles were collected by filtration and washed with acetone to remove the unreacted monomers and cross-linking agent, and dried under vacuum at The above prepared $\mathrm{SiO}_{2}-(\mathrm{E} 2+\mathrm{KH}-570)$ (150 $\mathrm{mg}$ ) were dispersed into $35 \mathrm{~mL}$ of THF under ultrasonication. MAA $(0.1 \mathrm{mmol})$, EGDMA and AIBN $(15 \mathrm{mg})$ were dissolved into this solution. The mixing solution was purged with nitrogen for $10 \mathrm{~min}$. Polymerization was first done at $50^{\circ} \mathrm{C}$ for $5 \mathrm{~h}$, and subsequently at $60^{\circ} \mathrm{C}$ for $24 \mathrm{~h}$. The mixing solution was stirred at a rate of $300 \mathrm{rpm} / \mathrm{min}$ throughout the experiment. Then particles were collected by filtration and washed with acetone to remove the unreacted monomers and cross-linking agent, and dried under vacuum at $\mathrm{SiO}_{2} @ M I P 1-E 2, \mathrm{SiO}_{2} @ M I P 2-E 2$, $\mathrm{SiO}_{2} @ \mathrm{MIP} 3-\mathrm{E} 2$, respectively.

In order to remove the E2 templates in the imprinted shells, SiO $@$ @MIP-E2 $(220 \mathrm{mg})$ was refluxed in the solution of DMSO and water $(5: 1, \mathrm{v} / \mathrm{v})$ at $180^{\circ} \mathrm{C}$ for $3 \mathrm{~h}$, and then the particles were obtained by Soxhlet extraction with the mixed methanol and acetic acid (8:2, v/v) solution at room temperature for $24 \mathrm{~h}$. The resultant nanoparticles were centrifuged, filtered and washed several times with methanol. The solids were vacuum dried at $60^{\circ} \mathrm{C}$ for $24 \mathrm{~h}$. The samples obtained with different $\mathrm{SiO}_{2} @ M I P-E 2$ ( $\left.\mathrm{SiO}_{2} @ M I P 1-E 2, \mathrm{SiO}_{2} @ M I P 2-E 2, \mathrm{SiO}_{2} @ M I P 3-E 2\right)$ were denoted as $\mathrm{SiO}_{2} @ M I P 1, \mathrm{SiO}_{2} @ \mathrm{MIP} 2, \mathrm{SiO}_{2} @ \mathrm{MIP} 3$ respectively. Nonimprinted nanoparticles were prepared via the same procedure of $\mathrm{SiO}_{2} @ \mathrm{MIP} 2$, but the $\mathrm{SiO}_{2}$-(IPTES+KH-570) (150 mg) was used in place of $\mathrm{SiO}_{2}-(\mathrm{E} 2+\mathrm{KH}-570)$, and assigned as $\mathrm{SiO}_{2} @ \mathrm{NIP} 1$. Moreover, as a control, $\mathrm{SiO}_{2} @ \mathrm{MIP} 4$ was also prepared in the same way as $\mathrm{SiO}_{2} @ \mathrm{MIP} 2$ without adding MAA.

\subsection{Adsorption Experiments of E2}

The equilibrium adsorption experiments were performed to evaluate the binding capability of four kinds of $\mathrm{SiO}_{2} @ \mathrm{MIP}\left(\mathrm{SiO}_{2} @ \mathrm{MIP} 1, \mathrm{SiO}_{2} @ \mathrm{MIP} 2, \mathrm{SiO}_{2} @ \mathrm{MIP}\right.$, $\left.\mathrm{SiO}_{2} @ \mathrm{MIP} 4\right)$ and $\mathrm{SiO}_{2} @ \mathrm{NIP} 1$. Standard E2 solutions were prepared in acetoni- 
trile and the E2 concentrations in the solutions were varied from $2 \mathrm{mg} / \mathrm{L}$ to 40 mg/L $\left(2,5,10,15,20,30,40\right.$ mg/L). Then the 10 mg of $\mathrm{SiO}_{2} @ M I P$ or $\mathrm{SiO}_{2} @ N I P 1$ were dispersed into $10 \mathrm{~mL}$ of standard E2 solution. The obtained mixture was incubated at room temperature for $24 \mathrm{~h}$, the suspension was filtered by the 0.1 $\mu \mathrm{m}$ micro-filter, and the filtered solution was analyzed by HPLC to obtain the E2 concentration.

In order to investigate the kinetics property of $\mathrm{SiO}_{2} @ \mathrm{MIP} 2$, the adsorption kinetic experiments were performed as follows. E2 solutions were prepared in acetonitrile and the E2 concentration in the solution was $37 \mu \mathrm{mol} / \mathrm{L}$. SiO $2 @ M I P 2$ (50 mg) or $\mathrm{SiO}_{2} @ \mathrm{NIP} 1$ (50 mg) were added into $10 \mathrm{~mL}$ of E2 solution. The obtained mixtures were conducted at room temperature for different contact time $(5,10,15,20,30,40,60 \mathrm{~min})$, respectively. The suspension was quickly filtered by the $0.1 \mu \mathrm{m}$ micro-filter, and the filtrates were analyzed by HPLC to obtain the E2 concentration.

Selectivity experiments were conducted by using E2, Lupeol (LU), 3',4',5'-trimethoxyflavanone (TF) and 2-Hydroxynaphthalene (Np) as the structural analogues of E2. The 10 mg of SiO ${ }_{2} @ M I P 2, S_{2} @ M I P 4$ and SiO $@ @ N I P 1$ were dispersed into $2 \mathrm{ml}$ of acetonitrile stock solution, which contains E2, LU, $\mathrm{TF}$ and $\mathrm{Np}$ at a concentration of $37 \mu \mathrm{mol} / \mathrm{L}$, respectively. After incubating for 24 $\mathrm{h}$ at room temperature, the suspension was filtered by the $0.1 \mu \mathrm{m}$ micro-filter, and the filtered solution was analyzed by HPLC to obtain the E2, LU, TF, Np concentration, respectively.

The reusability of $\mathrm{SiO}_{2} @ \mathrm{MIP} 2$ was measured as below: standard E2 solution was prepared in acetonitrile and the E2 concentrations in the solution were 10 mg/L. The SiO $@$ @MIP2 (100 mg) was dispersed into 20 mL of standard E2 solution. The mixture was incubated at room temperature for $24 \mathrm{~h}$, the suspension was filtered by the $0.1 \mu \mathrm{m}$ micro-filter. The filtrate was analyzed by HPLC. Then, the E2 of the recovered nanoparticles was removed with $10 \mathrm{~mL}$ of elution of methanol-acetic acid (8:2, v/v) for 24 hours to ensure complete removal of the $\mathrm{E} 2$ in the nanoparticles and washed with methanol, then vacuum dried at $60^{\circ} \mathrm{C}$ for $24 \mathrm{~h}$ and reused for the adsorption of E2. The adsorption regeneration cycle was repeated five times with the same $\mathrm{SiO}_{2} @ \mathrm{MIP} 2$.

\subsection{Instruments and HPLC Analysis}

Fourier transform infrared (FTIR) spectra were recorded with Perkin-Elmer system 2000 FT-IR spectrometer. ${ }^{1} \mathrm{H}$ and ${ }^{13} \mathrm{C}$ NMR spectra of EstSi were investigated by Bruker Ascend $400 \mathrm{MHz}$. Transmission electron microscopy (TEM) images were obtained on a Tecnai-G2-F20 electron microscope operating at 200 $\mathrm{kV}$. Morphology of the materials were determined by scanning electron microscopy (SEM) with a JEOL 6300-F microscope.

The Raman spectra were collected on a HORIBA Lab Raman spectrometer (France) with an excitation wavelength of $532 \mathrm{~nm}$, a resolution of $0.65 \mathrm{~cm}^{-1}$ and a beam diameter of $20 \mu \mathrm{m}$. Before Raman measurements, the SiO $@$ @MIP2 (10 $\mathrm{mg}$ ) or $\mathrm{SiO}_{2} @ \mathrm{NIP} 1$ (10 mg) was incubated in the $2 \mathrm{ml}$ of E2 acetonitrile solution 
(the E2 concentrations in the solution was $40 \mathrm{mg} / \mathrm{L}$ ) for $24 \mathrm{~h}$, then isolated by filtration, washed 3 times with acetonitrile and vacuum dried. The samples were denoted as $\mathrm{SiO}_{2} @ \mathrm{MIP} 2$ rebinding $\mathrm{E} 2$ and $\mathrm{SiO}_{2} @ \mathrm{NIP} 1$ rebinding E2, respectively. The Raman spectroscopy were recorded by focusing the $532 \mathrm{~nm}$ diode laser on the silica nanoparticle materials with a total exposure time of $300 \mathrm{~s}$ per spectrum, all spectrograms of samples were smoothed and the baselines were corrected.

A Shimazu Prominence LC-20 A HPLC (Kyoto, Japan) with an Acclaim 120-C18 column (Dionex, USA, $5 \mu \mathrm{m}, 120 \AA$, $4.6 \times 20 \mathrm{~mm}^{2}$ ). The UV detection wavelength was $208 \mathrm{~nm}$, the flow rate was $1.0 \mathrm{~mL} \cdot \mathrm{min}^{-1}$ and the injection volume was $25 \mu \mathrm{L}$. $\mathrm{ACN} / \mathrm{H}_{2} \mathrm{O}(45 / 55, \mathrm{v} / \mathrm{v})$ was used as the mobile phase.

\section{Results and Discussion}

\subsection{Preparation}

The covalently modified estradiol-functional monomer (EstSi) was synthesized according to the Yang et al.'s method (Figure 1) [25]. $\mathrm{SiO}_{2}$ nanoparticles were synthesized according to reference [24]. The covalently modified templates (Est$\mathrm{Si}$ ) along with $\mathrm{KH}-570$ were grafted onto the surface of $\mathrm{SiO}_{2}$ nanoparticles and followed by polymerization to result in a MIPs layer on the surface of $\mathrm{SiO}_{2}$ nanoparticles [26]. The thickness of the MIPs layer was controlled by the added cross linker and the number of imprinted sites was controlled by EstSi used. The quality of the imprinted sites was controlled by both the covalently fixed template and coupling reagent (KH-570). The ratio of EstSi/KH-570 was optimized as 1:2. Finally, the template was removed by heating the $\mathrm{SiO}_{2} @ M I P-E 2$ in DMSO at $180^{\circ} \mathrm{C}$, followed by Sohlex extraction with a mixed solvent of methanol and acetic acid [25] [26]. The preparation process was illustrated in Figure 2.

\subsection{Characterization of the $\mathrm{SiO}_{2} @ \mathrm{MIP}$}

The size and morphology of $\mathrm{SiO}_{2}$ nanoparticles were characterization by SEM (Figure 3). The as-synthesized $\mathrm{SiO}_{2}$ nanoparticles were uniform in both size and

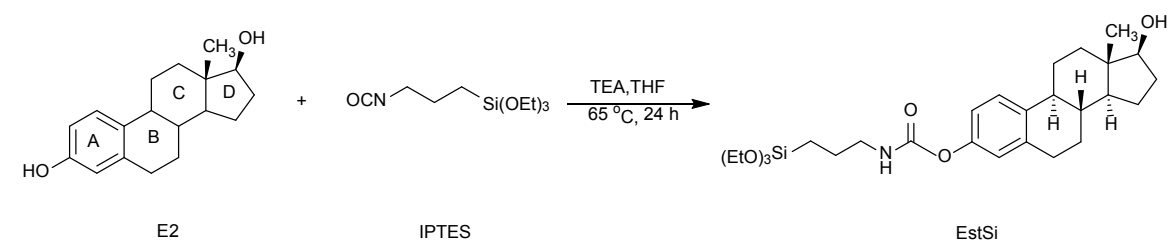

Figure 1. Synthesis of the template-functional monomer complex (EstSi).

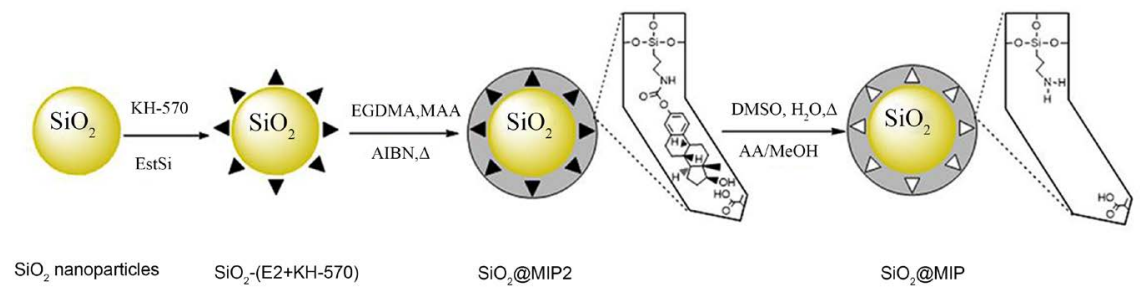

Figure 2. Schematic demonstration of the core-shell imprinting process. 


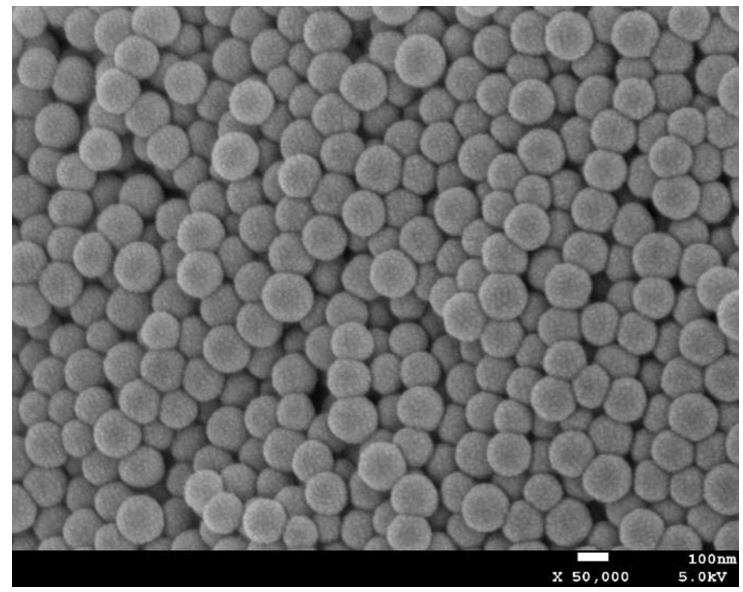

Figure 3. SEM images of $\mathrm{SiO}_{2}$ nanoparticle.

shape, with a mean diameter of about $100 \mathrm{~nm}$ and relatively mono-disperse. They were used for further grafting of EstSi and KH-570.

Fourier Transform Infrared (FTIR) spectroscopy was used to identify functional groups of $\mathrm{KH}-570$ grafted on $\mathrm{SiO}_{2}-(\mathrm{E} 2+\mathrm{KH}-570)$ and polymerized core-shell $\mathrm{SiO}_{2} @ M I P$ (Figure 4). FT-IR spectra of $\mathrm{SiO}_{2}-(\mathrm{E} 2+\mathrm{KH}-570)$ shows the characteristic band of $\mathrm{C}=\mathrm{O}$ stretching vibration in the $1700 \mathrm{~cm}^{-1}$ region, which indicates the presence of the coupling reagent (KH-570) [27]. After polymerization with EGDMA and MAA, a new peak at $1733 \mathrm{~cm}^{-1}$ appears, which could be assigned to the $\mathrm{C}=\mathrm{O}$ stretching (Figure 4, $\mathrm{SiO}_{2} @ M I P 2$ ), which verified the successful introduction of the functional groups onto the surfaces of the modified $\mathrm{SiO}_{2}$ nanoparticles by copolymerization [26] [27].

TEM images were obtained for $\mathrm{SiO}_{2}, \mathrm{SiO}_{2} @ M I P 1, \mathrm{SiO}_{2} @ M I P 2$ and $\mathrm{SiO}_{2} @ M I P 3$ to identify the core-shell structure (Figure 5). TEM images show that the thickness of the polymer layer of $\mathrm{SiO}_{2} @ \mathrm{MIP} 1$ (Figure 5(b)), $\mathrm{SiO}_{2} @ \mathrm{MIP} 2$ (Figure 5(c)), $\mathrm{SiO}_{2} @ \mathrm{MIP} 3$ (Figure 5(d)) was about $1.0 \pm 0.2 \mathrm{~nm}, 2.0 \pm 0.8 \mathrm{~nm}, 5.0 \pm 2.0$ $\mathrm{nm}$, respectively. These results indicate the thickness of the polymer shell depends on the amount of EGDMA used.

Raman spectra were used to confirm the incorporation of the template molecules (E2) in the $\mathrm{SiO}_{2} @ M I P 2-\mathrm{E} 2$ and removal of E2 from $\mathrm{SiO}_{2} @ M I P 2$. As shown in Figure 6, the $\mathrm{SiO}_{2} @ M I P 2-E 2$ exhibited strong characteristic Raman bands of $\mathrm{SiO}_{2} @ \mathrm{MIP} 2-\mathrm{E} 2$ around $829 \mathrm{~cm}^{-1}, 930 \mathrm{~cm}^{-1}, 1450 \mathrm{~cm}^{-1}$ (Figure 6(b)), indicating the successful incorporation of E2 in $\mathrm{SiO}_{2} @ M I P 2-\mathrm{E} 2$ (Figure 6(a) and Figure $6(\mathrm{~b}))$. The disappearance of the typical signals of E2 at $829 \mathrm{~cm}^{-1}, 930 \mathrm{~cm}^{-1}, 1450$ $\mathrm{cm}^{-1}$ from Figure $6(\mathrm{c})$, implicating that E2 was indeed removed from the polymer shell of $\mathrm{SiO}_{2} @ \mathrm{MIP} 2$. The main bands of these Raman spectra and their assignments are shown in Table 1 [28].

\subsection{Binding Property Investigation of the $\mathrm{SiO}_{2} @ \mathrm{MIP}$}

The adsorption capacity was calculated according to the following equation:

$$
Q=\left(C_{0}-C_{f}\right) V / M
$$




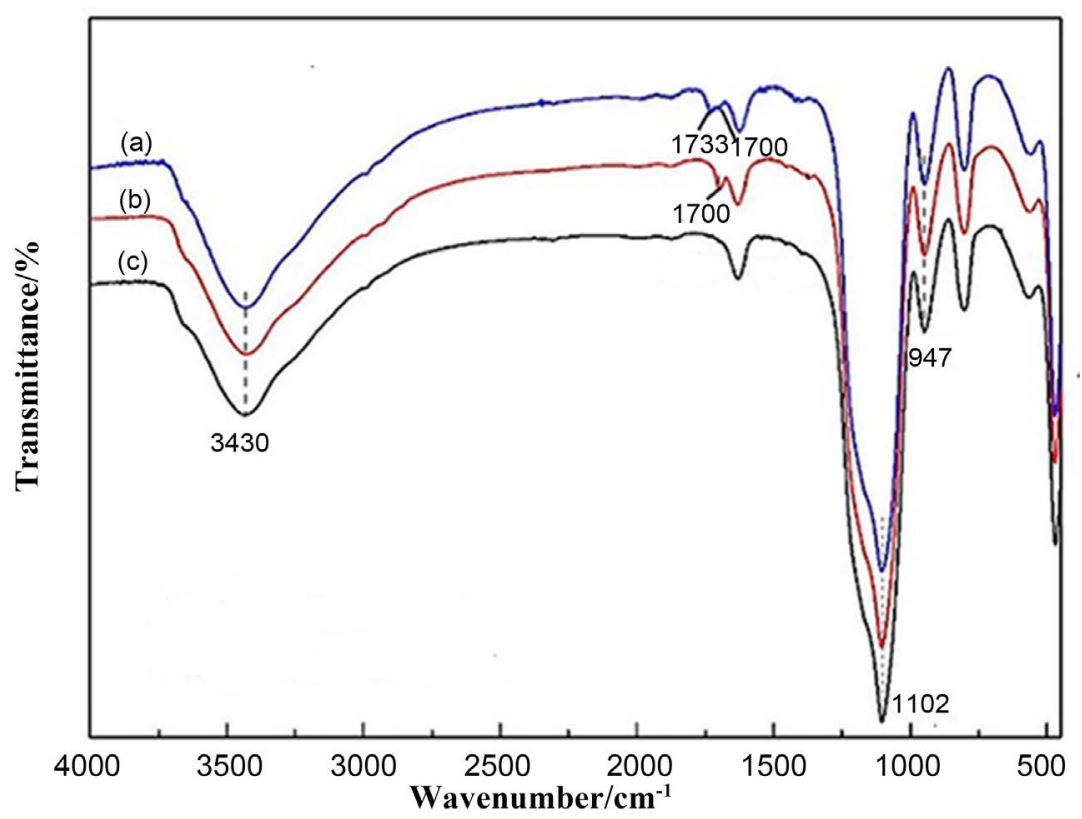

Figure 4. FT-IR spectra of nanoparticles: (a) The pure $\mathrm{SiO}_{2}$ nanoparticles; (b) $\mathrm{SiO}_{2}-(\mathrm{E} 2+\mathrm{KH}-570)$; (c) $\mathrm{SiO}_{2} @ \mathrm{MIP} 2$.
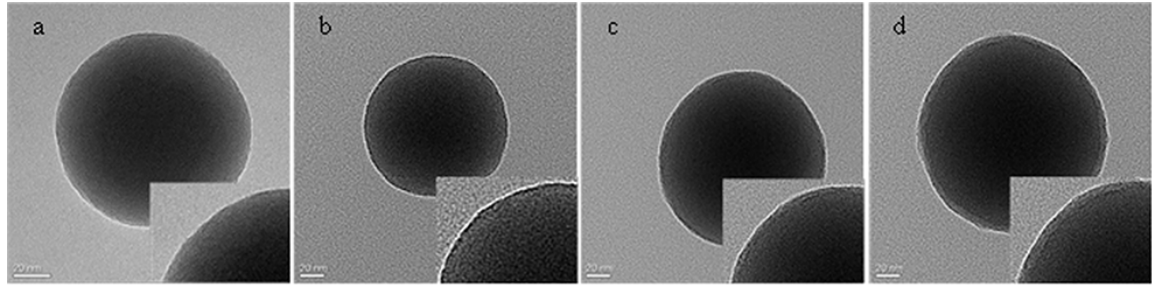

Figure 5. TEM images of nanoparticles: (a) pure $\mathrm{SiO}_{2}$ nanoparticles; (b) $\mathrm{SiO}_{2} @ \mathrm{MIP} 1$; (c) SiO2@MIP2; (d) SiO $@$ @MIP3.

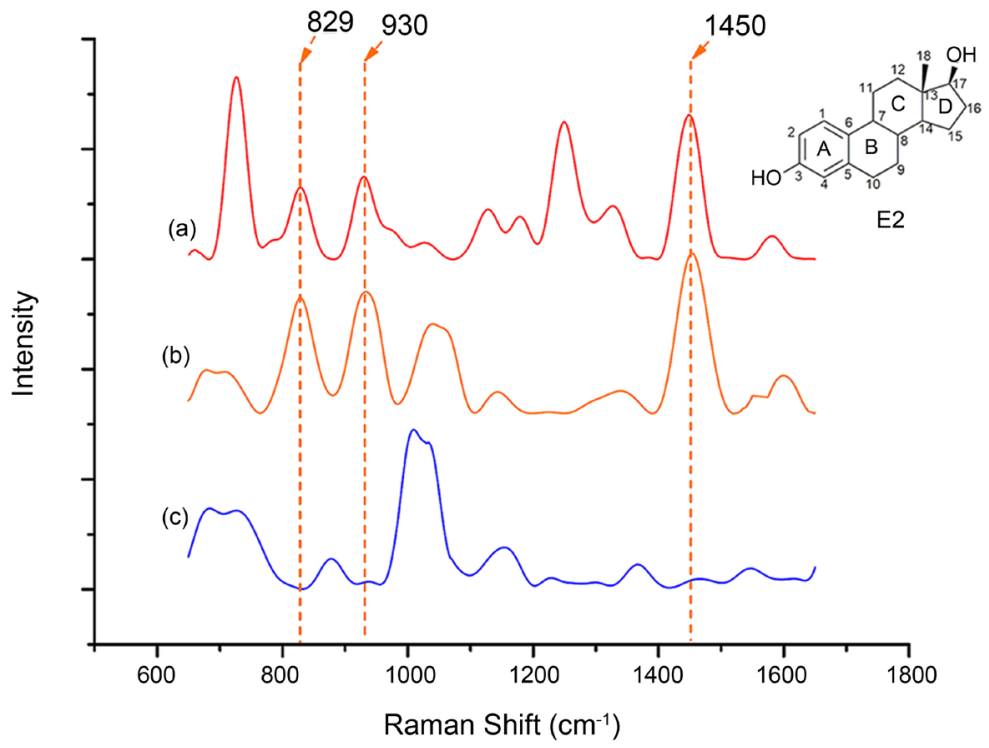

Figure 6. Raman spectroscopy of: (a) E2 standard sample; (b) $\mathrm{SiO}_{2} @ M I P 2-\mathrm{E} 2$; (c) $\mathrm{SiO}_{2} @ \mathrm{MIP} 2$. 
Table 1. Raman spectral assignment for the E2 solid.

\begin{tabular}{cc}
\hline The peak of Raman spectral $\left(\mathrm{cm}^{-1}\right)$ & Assignment \\
\hline 829 & $\delta_{\mathrm{s}}(\mathrm{C} 1, \mathrm{C} 2-\mathrm{H})$ \\
930 & $\delta_{\mathrm{as}}(\mathrm{C} 1, \mathrm{C} 2-\mathrm{H})$ \\
1450 & $v(\mathrm{C}-\mathrm{C}-\mathrm{H}) \mathrm{B}, \mathrm{C}, \mathrm{D}$ \\
& $v(\mathrm{C}-\mathrm{C}-\mathrm{H}) \mathrm{A}$ \\
\hline
\end{tabular}

$v$-stretching vibration; $\delta$-internal deformation vibration (bending); the schematic diagram of the E2 molecule in Figure 6.

where $C_{0}(\mathrm{mmol} / \mathrm{L})$ is the initial con-centration of $\mathrm{E} 2, C_{f}(\mathrm{mmol} / \mathrm{L})$ is the concentration of $\mathrm{E} 2$ in the filtrate, $V(\mathrm{~mL})$ is the volume of the adsorption mixture, and $\mathrm{M}(\mathrm{mg})$ is the mass of $\mathrm{SiO}_{2} @ \mathrm{MIP} 2$.

The isotherm of imprinted materials with added acrylic acid with shell thickness of 1 nm, 2 nm and 5 nm (Figure 7(b) $\mathrm{SiO}_{2} @ M I P 1$, Figure 7(c) $\mathrm{SiO}_{2} @ M I P 2$ and Figure 7(d) $\mathrm{SiO}_{2} @ M I P 3$ ), without acrylic acid of shell thickness of $2 \mathrm{~nm}$ (Figure7(e) $\left.\mathrm{SiO}_{2} @ M I P 4\right)$, and non-imprinted material (Figure 7(a) $\mathrm{SiO}_{2} @ \mathrm{NIP}$ ) are presented in Figure 7, which clearly demonstrate that the material with added acrylic acid of imprinted shell thickness of $2 \mathrm{~nm}$ gave the highest adsorption of E2 (Figure 7(c)). The one without added acrylic acid (Figure 7(e)) otherwise identical with $\mathrm{c}$ showed a slightly lower adsorption than $\mathrm{c}$. The shell thickness thicker or thinner than $2 \mathrm{~nm}$ showed poorer adsorption. The non-imprinted material had very low adsorption capacity for E2, due to non-specific adsorption. Thus, the material with added acrylic acid with thickness of $2 \mathrm{~nm}$ was used for further investigation in the adsorption kinetics and selectivity.

The core-shell imprinted material showed fast adsorption as demonstrated in Figure 8. The adsorption capacity of $\mathrm{SiO}_{2} @ \mathrm{MIP} 2$ increased quickly at the first 5 mins and reached equilibrium after 10 mins. For $\mathrm{SiO}_{2} @ \mathrm{NIP} 1$, the equilibrium time was 15 mins and the binding capacity was much lower than $\mathrm{SiO}_{2} @ \mathrm{MIP} 2$. This phenomenon can be explained by that comparing with the $\mathrm{SiO}_{2} @ \mathrm{NIP1}$, $\mathrm{SiO}_{2} @ \mathrm{MIP} 2$ have the specific binding sites for E2. The rapidly rebinding kinetics suggested $\mathrm{SiO}_{2} @ \mathrm{MIP} 2$ has great potential in ultrafast enrichment and separation of E2 molecules.

The detection limit of the as-synthesized material was further tested with the Raman intensity changes after adding different concentrations of E2, as exhibited in Figure 9. The peaks at 829,930 and $1450 \mathrm{~cm}^{-1}$ were selected for identifying E2. As the E2 concentration increased from $0.01 \mu \mathrm{mol} / \mathrm{L}$ to $1 \mu \mathrm{mol} / \mathrm{L}$, the peak signals intensity slightly increased, with the lowest detectable concentration of $0.01 \mu \mathrm{mol} / \mathrm{L}$, which was sufficient to meet the requirements of detection limit of $\mathrm{E} 2$ requirements in the environmental water samples.

The imprinting effects were further evaluated by adsorption specificity experiment for the template and its structural analogues, LU, TF and Np whose chemical structural formulae are shown in Figure10(a). The results were summarized in Figure 10(b). The adsoption ability of the non-imprinted material $\mathrm{SiO}_{2} @ \mathrm{NIP} 1$ for E2 was much lower than the $\mathrm{SiO}_{2} @ \mathrm{MIPs}$, and there was no significant difference in 


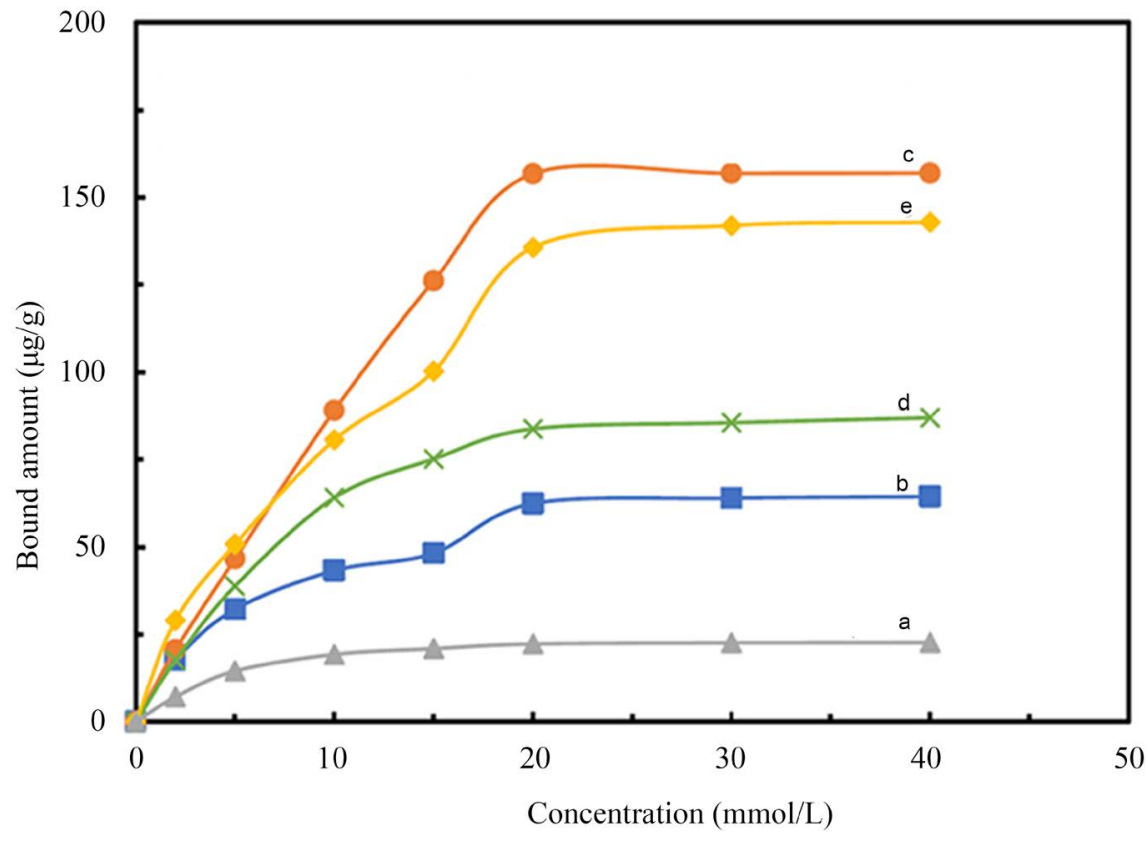

Figure 7. Adsorption isotherms: (a) $\mathrm{SiO}_{2} @ N I P 1 ;$ (b) $\mathrm{SiO}_{2} @ M I P 1 ;$ (c) $\mathrm{SiO}_{2} @ M I P 2$; (d) $\mathrm{SiO}_{2} @ \mathrm{MIP} 3$; (e) $\mathrm{SiO}_{2} @ \mathrm{MIP} 4$.

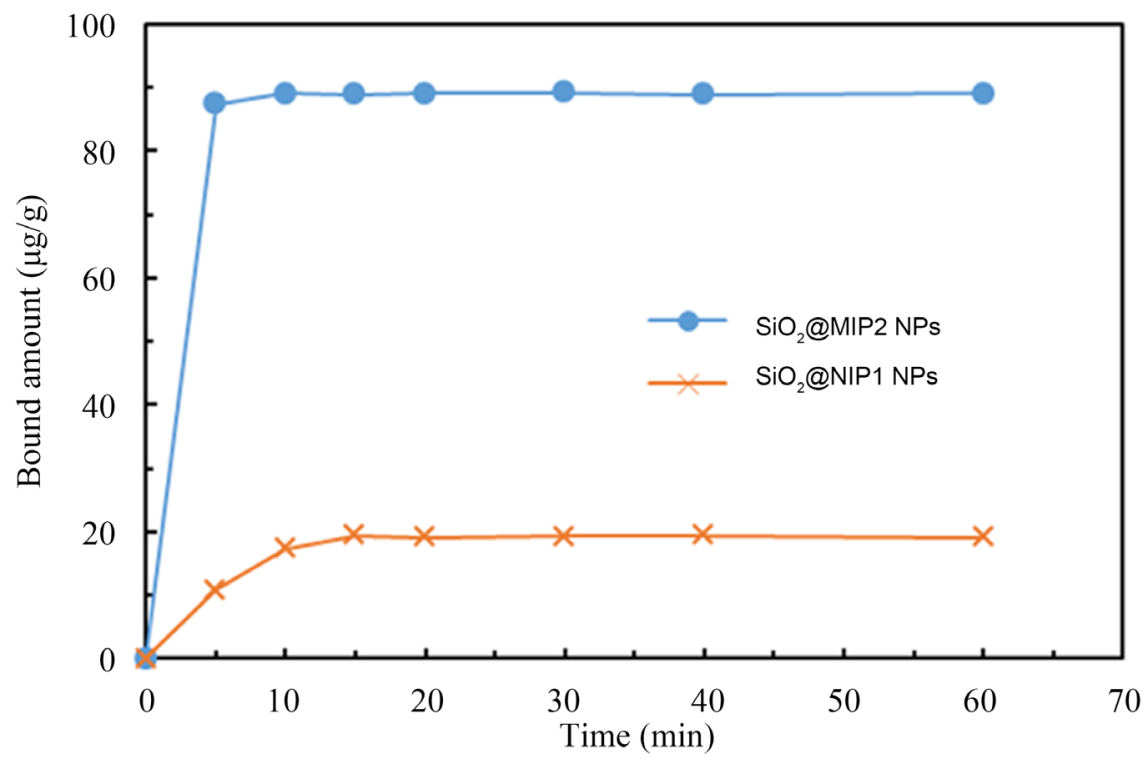

Figure 8. Kinetic curves of $\mathrm{SiO}_{2} @ \mathrm{MIP} 2$ and $\mathrm{SiO}_{2} @ \mathrm{NIP} 1$.

binding capacity for the competitive compounds.

The reusability of the materials is an important factor to improve the economic efficiency and extend practical uses. The adsorption-desorption cycles were repeated five times by regenerating the used imprinted. The reusability was evaluated according to the following equation:

$$
R=Q_{n} / Q_{0} \times 100 \%
$$

where $R$ is regeneration efficiencies, the $Q_{n}(\mu \mathrm{g} / \mathrm{g})$ is the adsorption capacity of 


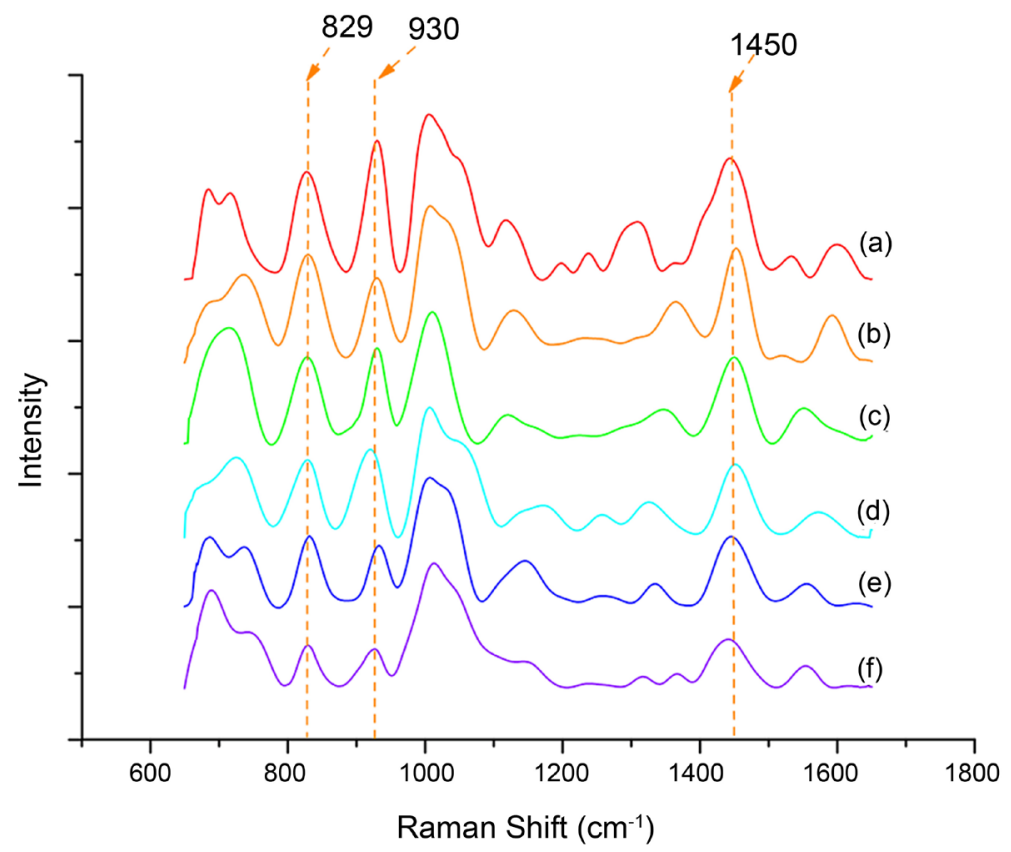

Figure 9. Raman spectra of $\mathrm{SiO}_{2} @ M I P 2$ incubated with E2 acetonitrile solution at concentration of (a) $1 \mu \mathrm{mol} / \mathrm{L}$; (b) $0.5 \mu \mathrm{mol} / \mathrm{L}$; (c) $0.1 \mu \mathrm{mol} / \mathrm{L}$; (d) $0.05 \mu \mathrm{mol} / \mathrm{L}$; (e) 0.025 $\mu \mathrm{mol} / \mathrm{L}$; (f) $0.01 \mu \mathrm{mol} / \mathrm{L}$, respectively.

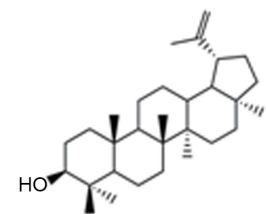

LU<smiles>C[C@]1(O)CCC2C3CCC4CC(O)CCC4C3CCC21</smiles>

E2<smiles>COc1cc(C2CC(=O)C3CCCC3O2)cc(O)c1O</smiles>

TF<smiles>Oc1ccc2ccccc2c1</smiles>

$\mathrm{Np}$

(a)

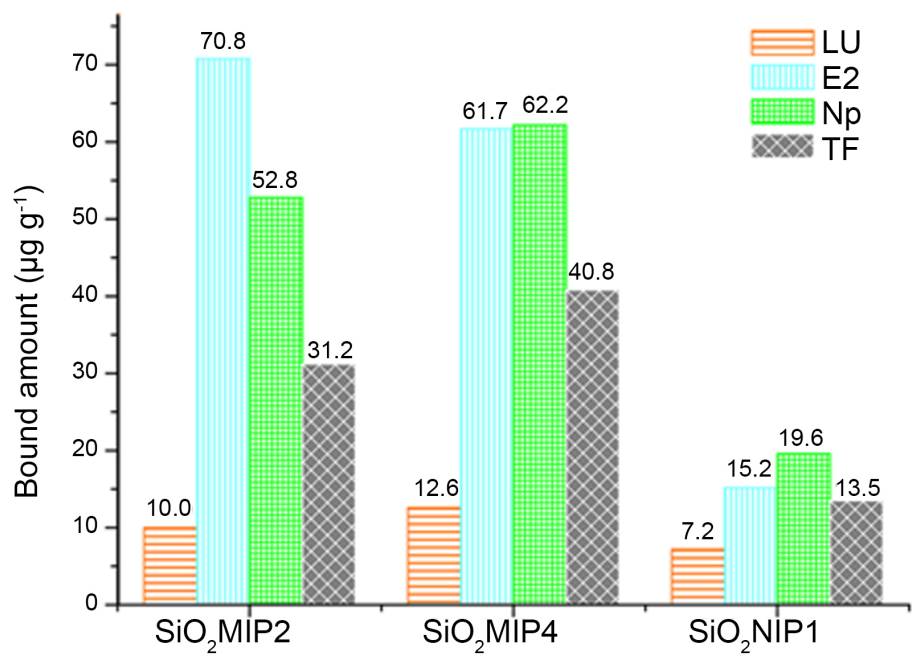

(b)

Figure 10. (a) The structure of the compounds used in the selectivity adsorption; (b) Selectivity adsorption result of four kinds of molecularly imprinted materials for E2, LU, Np and $\mathrm{TF}$. 


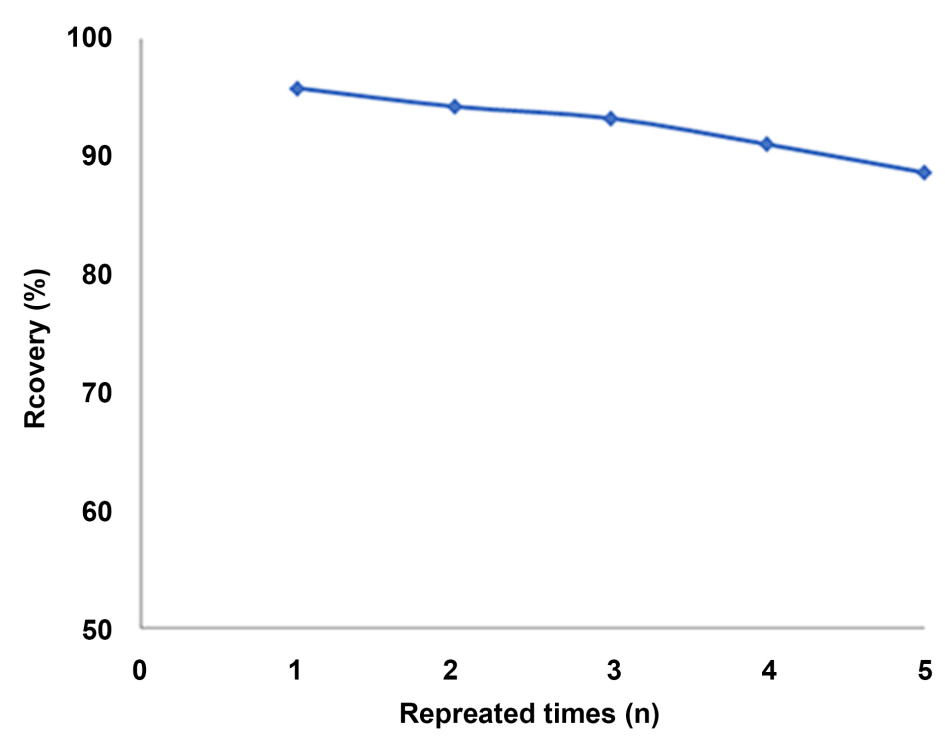

Figure 11. Reusability of the $\mathrm{SiO}_{2} @ \mathrm{MIP} 2$ material.

regenerative experiments, the " $n$ " is repeated times, $Q_{0}(\mu \mathrm{g} / \mathrm{g})$ is the adsorption capacity of original material.

As observed in Figure 11, calculations showed that of the prepared $\mathrm{SiO}_{2} @ \mathrm{MIP} 2$ after using for 5 times, the absorption capacity was reduced by about 10.6\%. The $\mathrm{SiO}_{2} @$ MIP2 were repeatedly used and regenerated for 5 times with no significant loss of its original adsorb ability and selectivity. $\mathrm{SiO}_{2} @ \mathrm{MIP} 2$ as a recyclable economic material has a potential applying prospect in the extraction, separation and concentration and trace analysis of $17 \beta$-estradiol. It is because that the appropriate thickness and the high stability of the polymer layer, and monolayer recognition sites are distributed uniformly on the surface of silica nanoparticles all can enhance reusability.

\section{Conclusion}

In summary, we have developed a core-shell silica-MIPs absorbent through anchoring a MIPs layer to the surface of $\mathrm{SiO}_{2}$ nanoparticles via a surface molecular imprinting process. The quantity and quality of imprinted sites on the surface of silica nanoparticle were ensured by covalently attached template precursors and coupling reagent $\mathrm{KH}-570$ on $\mathrm{SiO}_{2}$ before polymerized imprinting. This material, combining with Raman spectra as detection method, can fast and selectively identify E2 among structural analogues, with detection limit of 0.01 $\mu \mathrm{mol} / \mathrm{L}$. This method can be adapted for other environmental contaminates or biological significant molecules detection by simply switch the template in the shell imprinting process.

\section{Acknowledgements}

Financial supports from Science and Technology Department of Sichuan Province (2016JY0034, 2017SZ0075) is gratefully acknowledged. 


\section{Conflicts of Interest}

The authors declare no conflicts of interest regarding the publication of this paper.

\section{References}

[1] Ankley, G.T., Feifarek, D., Blackwell, B., et al. (2017) Re-Evaluating the Significance of Etrone as an Environmental Estrogen. Environmental Science \& Technology, 51, 4705. https://doi.org/10.1021/acs.est.7b00606

[2] Park, C.B., Aoki, J.Y., Lee, J.S., et al. (2010) The Effects of $17 \beta$-Estradiol on Various Reproductive Parameters in the Hermaphrodite Fish Kryptolebias marmoratus. Aquatic Toxicology, 96, 273-279. https://doi.org/10.1016/j.aquatox.2009.11.006

[3] Jiang, L.H., Liu, Y.G., Zeng, G.M., et al. (2016) Removal of $17 \beta$-Estradiol by Few-Layered Graphene Oxide Nanosheets from Aqueous Solutions: External Influence and Adsorption Mechanism. Chemical Engineering Journal, 284, 93-102. https://doi.org/10.1016/j.cej.2015.08.139

[4] Fernández, L., Borzecka, W., Lin, Z., et al. (2017) Nanomagnet-Photosensitizer Hybrid Materials for the Degradation of $17 \beta$-Estradiol in Batch and Flow Modes. Dyes and Pigments, 142, 535-543. https://doi.org/10.1016/j.dyepig.2017.04.010

[5] Li, R., Liu, Y., Yan, T., et al. (2015) A Competitive Photo Electrochemical Assay for Estradiol Based on in Situgenerated CdS-Enhanced $\mathrm{TiO}_{2}$. Biosensors \& Bioelectronics, 66, 596-602. https://doi.org/10.1016/j.bios.2014.12.002

[6] Qin, C., Troya, D., Shang, C., Hildreth, S., Helm, R. and Xia, K. (2015) Surface Catalyzed Oxidative Oligomerization of $17 \beta$-Estradiol by $\mathrm{Fe}^{3+}$-Saturated Montmorillonite. Environmental Science \& Technology, 49, 956-964.

https://doi.org/10.1021/es504815t

[7] Lloret, L., Eibes, G., Lú-Chau, T.A., Moreira, M.T., Feijoo, G. and Lema, J.M. (2010) Laccase-Catalyzed Degradation of Anti-Inflammatories and Estrogens. Biochemical Engineering Journal, 51, 124-131. https://doi.org/10.1016/j.bej.2010.06.005

[8] Li, J., Zhang, Y., Huang, Q., et al. (2017) Degradation of Organic Pollutants Mediated by Extra Cellular Peroxidase in Simulated Sunlit Humic Waters: A Case Study with 17beta-Estradiol. Journal of Hazardous Materials, 331, 123-131. https://doi.org/10.1016/j.jhazmat.2017.02.033

[9] Fernandez, L., Louvado, A., Esteves, V.I., Gomes, N.C.M., Almeida, A. and Cunha, A. (2017) Biodegradation of 17beta-Estradiol by Bacteria Isolated from Deep Sea Sediments in Aerobic and Anaerobic Media. Journal of Hazardous Materials, 323, 359-366. https://doi.org/10.1016/j.jhazmat.2016.05.029

[10] Vansant, E., Van Der, Voort, P. and Vrancken, K. (1995) Characterization and Chemical Modification of the Silica Surface. Applied Catalysis A: General, Elsevier Science, 131, 556.

[11] Hartono, S.B., Gu, W., Kleitz, F., et al. (2012) Poly-l-lysine Functionalized Large Pore Cubic Mesostructured Silica Nanoparticles as Biocompatible Carriers for Gene Delivery. ACS Nano, 6, 2104-2117. https://doi.org/10.1021/nn2039643

[12] Yang, C., Yan, X., Guo, H. and Fu, G. (2016) Synthesis of Surface Protein-Imprinted Nanoparticles Endowed with Reversible Physical Cross-Links. Biosensors and Bioelectronics, 75, 129-135. https://doi.org/10.1016/j.bios.2015.08.033

[13] Zhang, M., He, J., Shen, Y., et al. (2018) Application of Pseudo-Template Molecularly Imprinted Polymers by Atom Transfer Radical Polymerization to the Solid-Phase Extraction of Prethroids. Talanta, 178, 1011-1016. 
https://doi.org/10.1016/j.talanta.2017.08.100

[14] Ma, W. and Row, K.H. (2018) Solid-Phase Extraction of Chlorophenols in Seawater using a Magnetic Ionic Liquid Molecularly Imprinted Polymer with Incorporated Silicon Dioxide as a Sorbent. Journal of chromatography $A, 1559,78-85$. https://doi.org/10.1016/j.chroma.2018.01.013

[15] Thongchai, W. and Fukngoen, P. (2018) Synthesis of Curcuminoid-Imprinted Polymers Applied to the Solid-Phase Extraction of Curcuminoids from Turmeric Samples. Journal of Pharmaceutical Analysis, 8, 60-68. https://doi.org/10.1016/j.jpha.2017.09.003

[16] Hosoya, K., Shirasu, Y., et al. (1998) Molecularly Imprinted Chiral Stationary Phase Prepared with Racemic Template. Analytical Chemistry, 70, 943-945.

https://doi.org/10.1021/ac9707038

[17] Rutkowska, M., Płotka-Wasylka, J., Morrison, C., Wieczorek, P.P., Namieśnik, J. and Marć, M. (2018) Application of Molecularly Imprinted Polymers in Analytical Chiral Separations and Analysis. TrAC Trends in Analytical Chemistry, 102, 91-102. https://doi.org/10.1016/j.trac.2018.01.011

[18] Lin, X.H., Aik, S.X.L., Angkasa, J., Le, Q., Chooi, K.S. and Li, S.F.Y. (2018) Selective and Sensitive Sensors Based on Molecularly Imprinted Poly (vinylidene fluoride) for Determination of Pesticides and Chemical Threat Agent Simulants. Sensors and Actuators B: Chemical, 258, 228-237. https://doi.org/10.1016/j.snb.2017.11.070

[19] Wulff, G. (2002) Enzyme-Like Catalysis by Molecularly Imprinted Polymers. Chemical Reviews, 102, 1-28. https://doi.org/10.1021/cr980039a

[20] Markowitz, M.A., Kust, P.R., Deng, G. and Schoen, P.E. (2000) Catalytic Silica Particles via Template-Directed Molecular Imprinting. Langmuir, 16, 1759-1765. https://doi.org/10.1021/la990809t

[21] Guo, Y.X., Liu, Y.P., et al. (2004) Amino Acids Assisted Hydrothermal Synthesis of Hierarchically Structured $\mathrm{ZnO}$ with Enhanced Photo-Catalytic Activities. Applied Surface Science, 384, 83-91. https://doi.org/10.1016/j.apsusc.2016.04.036

[22] Schmidt, R.H., Mosbach, K. and Haup, K. (2016) A Simple Method for Spin-Coating Molecularly Imprinted Polymer Films of Controlled Thickness and Porosity. Advanced Materials, 16, 719-723. https://doi.org/10.1002/adma.200306374

[23] Huang, Q., Liu, M., Mao, L., et al. (2017) Surface Functionalized $\mathrm{SiO}_{2}$ Nanoparticles with Cationic Polymers via the Combination of Mussel Inspired Chemistry and Surface Initiated Atom Transfer Radical Polymerization: Characterization and Enhanced Removal of Organic Dye. Journal of Colloid and Interface Science, 499, 170-179. https://doi.org/10.1016/j.jcis.2017.03.102

[24] Stöber, W., Fink, A. and Bohn, E. (1968) Controlled Growth of Monodisperse Silica Spheres in the Micron Size Range. Journal of Colloid and Interface Science, 26, 62-69. https://doi.org/10.1016/0021-9797(68)90272-5

[25] Yang, H.H., Zhang, S.Q., Yang, W., et al. (2004) Molecularly Imprinted Sol-Gel Nanotubes Membrane for Biochemical Separations. Journal of the American Chemical Society, 126, 4054-4055. https://doi.org/10.1021/ja0389570

[26] Wang, X.Y., Chen, L.X., Kang, Q., et al. (2014) Novel Monodisperse Molecularly Imprinted Shell for Estradiol Based on Surface Imprinted Hollow vinyl-SiO 2 Particles. Talanta, 124, 7-13. https://doi.org/10.1016/j.talanta.2014.02.040

[27] He, M., Meng, M., Wan, J., He, J. and Yan, Y. (2012) A New Molecularly Imprinted Polymer Prepared by Surface Imprinting Technique for Selective Adsorption towards Kaempferol. Polym Bull, 68, 1039-1052. 
https://doi.org/10.1007/s00289-011-0605-x

[28] Xie, Y., Chen, D., Zhao, J., et al. (2012) An Efficient Hybrid Design to Prepare Highly Dense Imprinted Layer-Coated Silica Particles for Selective Uptake of Trace Metsulfuronmethyl from Complicated Matrices. RSC Advances, 2, 273-283. https://doi.org/10.1039/C1RA00438G 